\title{
Experimental and Quantum Chemical Studies on the Corrosion Inhibition Potential of Phthalic Acid for Mild Steel in $0.1 \mathrm{M} \mathrm{H}_{2} \mathrm{SO}_{4}$
}

Ameh $\mathrm{PO}^{1}$, Koha $\mathrm{PU}^{2}$ and Eddy $\mathrm{NO}^{3 *}$

${ }^{1}$ Department of Chemistry, Nigeria Police Academy, Wudil, Kano, Nigeria

${ }^{2}$ Department of Chemistry, University of Nigeria, Nsukka, Enugu State, Nigeria

${ }^{3}$ Department of Chemistry, Akwalbom State University, IkotAkpaeden, Akwalbom State, Nigeria

\begin{abstract}
The corrosion inhibition potential of phthalic acid for mild steel in $0.1 \mathrm{M}$ sulphuric acid was studied using experimental (weight loss, gasometric, FTIR and Scanning electron microscopy) and theoretical (semi empirical, Ab initio and DFT) approaches. Results obtained from weight loss measurements indicated that phthalic acid inhibited the corrosion of mild steel and recorded average and instantaneous maximum inhibition efficiencies of 55.48 and $87.34 \%$ at $303 \mathrm{~K}$ and at a concentration of $0.1 \mathrm{M}$ respectively. Thermodynamic/adsorption considerations revealed that the adsorption of the inhibitor is exothermic, spontaneous and supported the mechanism of physical adsorption. The adsorption behaviour of the inhibitor was best described by the Langmuir adsorption model. FTIR spectra obtained from the corrosion product of mild steel in the absence and presence of the inhibitor revealed the existence of interaction between the inhibitor and the metal surface due to some shifts in the functional groups of the compound after adsorption. Scanning electron micrographs of the corroded metal (in the absence and presence of the inhibitor) revealed that phthalic acid prevented the corrosion of mild steel by forming protective coverage on the surface of the metal. Calculated quantum chemical parameters were found to be in good agreement with those reported for some good corrosion inhibitors. Although results obtained from $\mathrm{Ab}$ initio calculations for condensed Fukui functions were slightly at variance with those obtained from DFT calculations, considerations of Huckel charges on the atoms of the molecule, bond length, HOMO and LUMO molecular orbital plots clearly supported DFT results which indicated that the sites for nucleophilic and electrophilic attacks corresponded to atoms $\mathrm{O}(11)$ and $\mathrm{C}(4)$ respectively.
\end{abstract}

Keywords: Corrosion; Inhibition; Phthalic acid; Experimental and quantum chemical studies

\section{Introduction}

Corrosion is an environmental problem that attacks most metals of industrial importance, especially when they come in contact with aggressive medium [1]. Acid corrosion of metals such as mild steel, aluminium and zinc have received wider concession and researches because several industrial installations (in metallurgical, fertilizer and oil refining industries) built from these metals are prone to corrosion attack during acid wash, etching, scale removal, etc [2]. In view of these and other effects, several inhibitors have been reportedly studied and applied to control the rate of corrosion of valuable metals and the results obtained have been encouraging. However, environmental and other concerns have shown that most of the common corrosion inhibitors are toxic, nonbiodegradable, expensive and are not easily available [3]. Mild steel is one of the widely used metals in industrial fabrications and sulphuric acid is a strong acid that can enhance its corrosion of mild steel within a short period of time. Therefore the present study is aimed at investigating the corrosion inhibition potential of phthalic acid for mild steel in sulphuric acid solution using experimental and theoretical approaches. Most corrosion inhibitors are compounds containing hetero atoms $(\mathrm{N}, \mathrm{O}, \mathrm{S}$ or $\mathrm{P})$ in aromatic or long carbon chain. Also, the presence of $\pi$-electron and suitable functional group can effectively enhances the inhibition efficiency of an inhibitor [4]. Figure 1 shows the molecular and optimised structure of phthalic acid. From the Figure, it can be seen that phthalic acid is expected to be a good corrosion inhibitor because it contain some hetero atoms $(\mathrm{O}$ atoms) in aromatic system. Studies on the use of phthalic acid is scanty, however, Dinnappa et al. [5] found that phthalic acid can effectively inhibit the interfacial corrosion of $\mathrm{Cu}$ in $\mathrm{HClO}_{4}$ medium. Similarly, Mohen et al. [6] inhibited the corrosion of $\mathrm{Zn}$ in acidic medium using phthalic acid. Experimental aspect of the work shall be achieved using weight loss, hydrogen evolution; Fourier transformed infrared spectroscopy and scanning electron microscopy while the theoretical aspect of the work shall be achieved using semi empirical, Ab initio and Density functional theory (DFT) models.

\section{Materials and Methods}

\section{Materials}

Materials used for the study were mild steel sheet of composition (wt \%, Mn (0.6), P (0.36), C (0.15) Si (0.03) and Fe (98.86). The sheet was mechanically pressed cut into different coupons, each of dimension, 5 $\mathrm{x} 4 \times 0.11 \mathrm{~cm}$. Each coupon was degreased by washing with ethanol, cleaned with acetone and allowed to dry in the air before preservation in a desiccator. All reagents used for the study were analar grade and well distilled water was used for their preparation. Concentration of $\mathrm{HCl}$ used for weight loss study was $0.1 \mathrm{M}$.

\section{Gravimetric method}

Gravimetric method is the most conventional method that can be used to study the corrosion of metals because, unlike other methods, it can give information on the average rate of corrosion and inhibition efficiency. In this work, gravimetric methods were carried out at 303 ,

*Corresponding author: Eddy NO, Department of Chemistry, Akwalbom State University, IkotAkpaeden, Akwalbom State, Nigeria, E-mail: nabukeddy@yahoo.com

Received June 23, 2015; Accepted June 25, 2015; Published July 02, 2015

Citation: Ameh PO, Koha PU, Eddy NO (2015) Experimental and Quantum Chemical Studies on the Corrosion Inhibition Potential of Phthalic Acid for Mild Steel in $0.1 \mathrm{M}$ $\mathrm{H}_{2} \mathrm{SO}_{4}$. Chem Sci J 6: 100. doi:10.4172/2150-3494.1000100

Copyright: ( 2015 Ameh PO, et al. This is an open-access article distributed under the terms of the Creative Commons Attribution License, which permits unrestricted use, distribution, and reproduction in any medium, provided the original author and source are credited. 
313,323 and $333 \mathrm{~K}$ for 7 days using the method described in literature [2]. From the average weight loss (mean of three replicate analyses) results, the inhibition efficiency (\%I) of the inhibitor, the degree of surface coverage $(\mathrm{q})$ and the corrosion rate of mild steel $(\mathrm{CR})$ were calculated using equations 1 to 3 respectively [7],

$$
\begin{aligned}
& \% I=\frac{w_{1}-w_{2}}{w_{1}} \times 100 \\
& \theta=\left[1-\frac{w_{1}}{w_{2}}\right] \\
& C R=\frac{w_{1}-w_{2}}{A t}
\end{aligned}
$$

Where $\mathrm{w}_{1}$ and $\mathrm{w}_{2}$ are the weight losses of mild steel (in grams) in the absence and presence of the inhibitor respectively ${ }^{\theta}$ is the degree of surface coverage of the inhibitor, CR is the corrosion rate of mild steel, A is the surface area of the mild steel coupon in $\mathrm{cm}^{2}$ and $\mathrm{t}$ is the period of immersion in hours.

\section{Gasometric method}

In gasometric experiment, the test solution (was poured into the reaction vessel. Upon the introduction of mild steel, the flask was quickly corked and the rise in volume of the paraffin due to hydrogen evolution was noted after every minute until a steady volume was observed. Inhibition efficiency was calculated as quotient of the difference between volume of hydrogen evolved (by the blank and that of the test solution) to the volume of hydrogen evolved by the blank.

\section{FTIR analysis}

FTIR analysis of the phthalic acid and those of the corrosion products (in the absence and presence of the inhibitor) were carried out using Scimadzu FTIR-8400S Fourier transform infra-red spectrophotometer. The sample was prepared in $\mathrm{K} \mathrm{Br}$ and the analysis was carried out by scanning the sample through a wave number range of 400 to $4000 \mathrm{~cm}^{-1}$.

\section{Scanning electron microscopy}

The morphology of the gum was studied with a JSM-5600 LV scanning electron microscope (SEM) of JEOL, Tokyo, Japan. The dried sample was mounted on a metal stub and sputtered with gold in order to make the sample conductive, and the images were taken at an accelerating voltage of $10 \mathrm{kV}$ using different magnifications.

\section{Quantum chemical calculations}

Full geometric optimization of phthalic acid was carried out using molecular mechanics, ab ignition and DFT level of theories in the HyperChem release 8.0 software. Semi-empirical parameters were calculated using optimized structure of phthalic acid as an input to the MOPAC software, while Muliken charges were calculated using HyperChem release 8.0 software. All quantum chemical calculations were carried out on gas phase.

\section{Results and Discussions}

\section{Variation of weight loss with time}

Figure 2 shows the variation of weight loss with time for the corrosion of mild steel in $0.1 \mathrm{M} \mathrm{H}_{2} \mathrm{SO}_{4}$ containing various concentrations of phthalic acid at $303,313,323$ and $333 \mathrm{~K}$ respectively. The plots generally reveal that weight loss of mild steel increases with increase in the period of contact but decreases with increase in concentration of phthalic acid indicating that the rate of corrosion of mild steel in solutions of $\mathrm{H}_{2} \mathrm{SO}_{4}$ increases with time but decreases with increase in the concentration of phthalic acid. A close examination of the plots also reveal that weight loss of mild steel increases with increase in temperature indicating that the rate of corrosion of mild steel increases with increase in temperature. Values of corrosion rate of mild steel and inhibition efficiency of phthalic acid for the corrosion of mild steel in various media are presented in Table 1 . The results show at a glance that the corrosion rate increases with increase in the period of contact but decreased with increase in the concentration of phthalic acid. Therefore, phthalic acid is an adsorption inhibitor for the corrosion of mild steel in solution of $\mathrm{H}_{2} \mathrm{SO}_{4}$ because its inhibition efficiency increases with increase in concentration [4]. Results obtained from gasometry measurements gave $52.30,64.44,68.23,72.81$ and $87.34 \%$ at concentrations of $0.002,0.004,0.006,0.008$ and $0.01 \mathrm{M}$ respectively, From the results obtained, the instantaneous inhibition efficiency of phthalic acid is better than its average inhibition efficiency, The results obtained in this work compares favourably with those obtained by Dinnappa et al. [5] and by Mohen et al. [6].

\section{Effect of temperature}

The effect of temperature on the corrosion of mild steel in the presence and absence of phthalic acid was investigated using the Arrhenius equation, which can be written as follows [8].

$$
C R=A \exp \left(\frac{-E_{a}}{R T}\right)
$$

Where CR is the corrosion rate of mild steel, A is the Arhenius or pre-exponential constant, $\mathrm{E}_{\mathrm{a}}$ is the activation energy, $\mathrm{R}$ is the gas constant and $\mathrm{T}$ is the temperature. From the logarithm of both sides of equation 4 , equation 5 was obtained,

$$
\ln (C R)=\ln A-\frac{}{R T}
$$

From equation 5 a plot of $\ln (\mathrm{CR})$ versus $1 / \mathrm{T}$ should be linear with slope and intercept equal to $\mathrm{E} / \mathrm{R}$ and $\ln \mathrm{A}$ respectively. Figure 3 shows the Arrhenius plot for the corrosion of mild steel in $1 \mathrm{M} \mathrm{H}_{2} \mathrm{SO}_{4}$ containing various concentrations of phthalic acid. Arrhenius parameters deduced from the plots are presented in Table 2. The results obtained, showed that $\mathrm{R}^{2}$ values for the plots ranged from 0.9689 to 0.9954 indicating a high degree of linearity. The activation energy calculated for the blank $(11.20 \mathrm{~J} / \mathrm{mol})$ was lower than those calculated for the inhibited systems (which ranged from 14.13 to $18.12 \mathrm{~J} / \mathrm{mol}$ ) confirming that the corrosion of mild steel in solution of $\mathrm{H}_{2} \mathrm{SO}_{4}$ is retarded by phthalic acid. Also, the activation energies are lower than the threshold value of 80 $\mathrm{kJ} / \mathrm{mol}$ required for the mechanism of chemical adsorption. Hence, the mechanism of adsorption of phthalic acid on the surface of mild steel is physical adsorption [9].<smiles>O=C(O)c1ccccc1C(=O)O</smiles>

Chemical structure

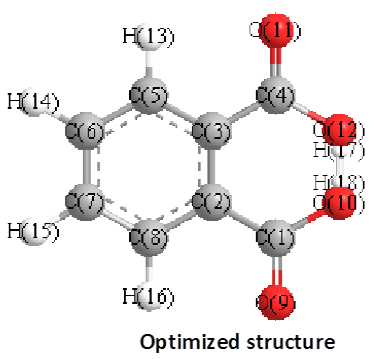

Figure 1: Molecular and optimised structures of phthalic acid. 


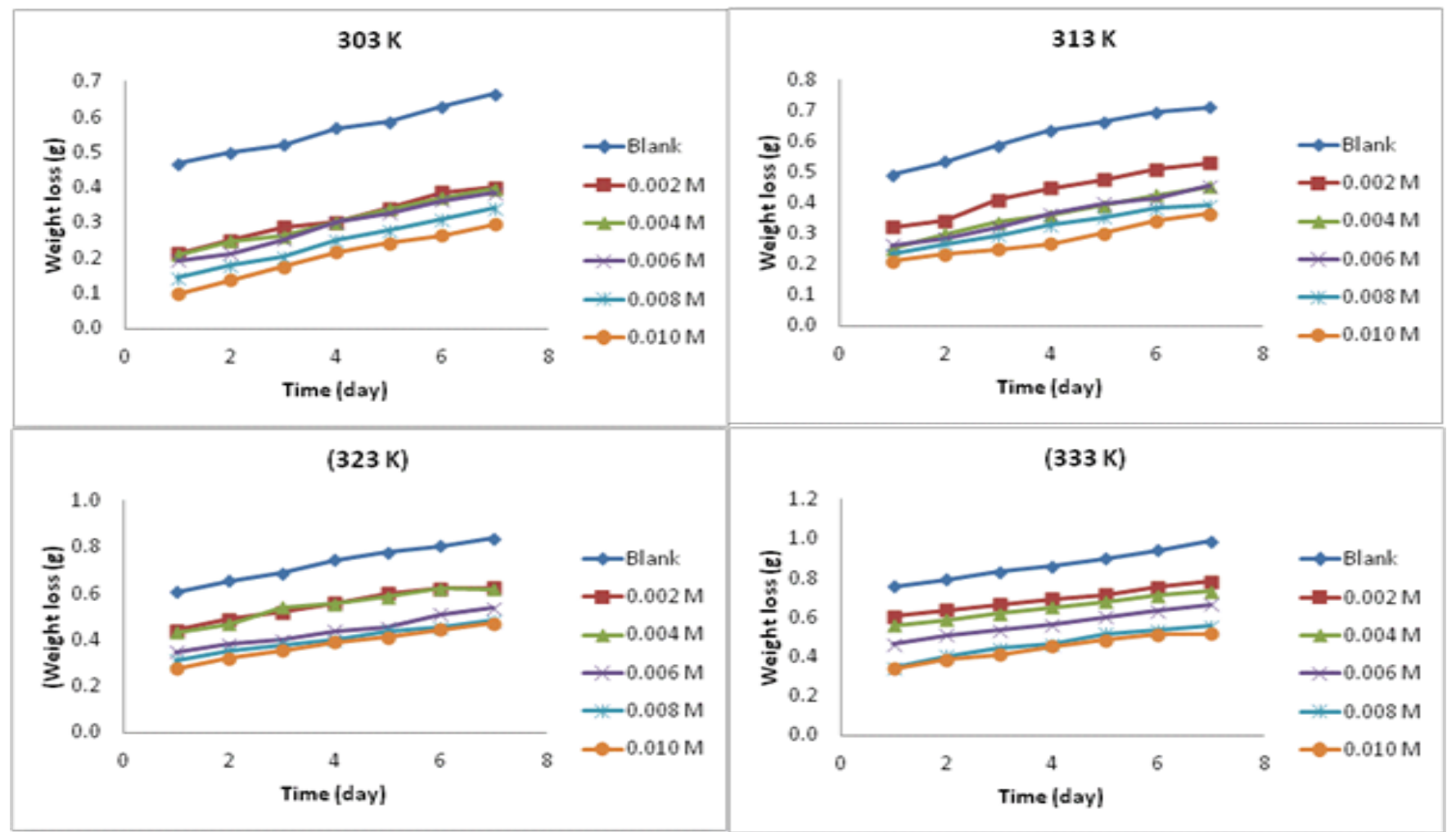

Figure 2: variation of weight loss with time for the corrosion of mild steel in $0.1 \mathrm{M} \mathrm{H}_{2} \mathrm{SO}_{4}$ containing various concentrations of phthalic acid at 303 to $333 \mathrm{~K}$.

\begin{tabular}{|c|c|c|c|c|c|c|c|c|}
\hline \multirow[t]{2}{*}{$\mathrm{C}(\mathrm{M})$} & \multicolumn{4}{|c|}{ Corrosion rate $\left(\mathrm{gcm}^{-2} \mathrm{~h}^{-1}\right)$} & \multicolumn{4}{|c|}{ Inhibition efficiency (\%) } \\
\hline & $303 \mathrm{~K}$ & $313 \mathrm{~K}$ & $323 \mathrm{~K}$ & $333 \mathrm{~K}$ & $303 \mathrm{~K}$ & $313 \mathrm{~K}$ & $323 \mathrm{~K}$ & $333 \mathrm{~K}$ \\
\hline Blank & 0.000198 & 0.000212 & 0.000249 & 0.000294 & - & - & - & - \\
\hline 0.002 & 0.000119 & 0.000158 & 0.000186 & 0.000233 & 39.70 & 25.46 & 25.30 & 20.75 \\
\hline 0.004 & 0.000118 & 0.000135 & 0.000185 & 0.000218 & 40.45 & 36.29 & 26.01 & 25.81 \\
\hline 0.006 & 0.000115 & 0.000135 & 0.00016 & 0.000198 & 42.11 & 36.01 & 35.80 & 32.79 \\
\hline 0.008 & 0.000102 & 0.000116 & 0.000144 & 0.000165 & 48.57 & 45.01 & 42.36 & 43.93 \\
\hline 0.1000 & 8.81E-05 & 0.000109 & 0.00014 & 0.000153 & 55.49 & 48.66 & 43.91 & 47.87 \\
\hline
\end{tabular}

Table 1: Corrosion rate of mild steel in $0.1 \mathrm{M} \mathrm{H}_{2} \mathrm{SO}_{4}$ and inhibition efficiency of phthalic acid for the corrosion of mild steel.

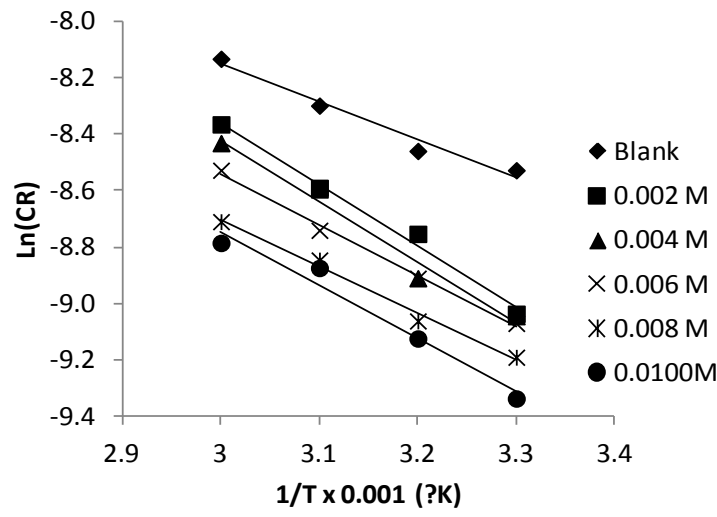

Figure 3: Arrhenius plot for the corrosion of mild steel in $0.1 \mathrm{M} \mathrm{H}_{2} \mathrm{SO}_{4}$ containing various concentrations of phthalic acid.

\section{Adsorption/thermodynamic considerations}

The transition state equation (equation 6) was used to calculate the enthalpy and entropy changes of adsorption [10].

$$
C R=\frac{R T}{N h} \exp \left(\frac{\Delta S_{a d s}^{0}}{R}\right) \exp \left(\frac{-\Delta H_{a d s}^{0}}{R T}\right)
$$

where $\mathrm{N}$ is the Avogadro's number, $\mathrm{h}$ is the plank constant, $\Delta S_{a d s}^{0}$ is the standard entropy change, $\Delta H_{a d s}^{0}$ is the standard enthalpy change, $\mathrm{R}$ is the gas constant and $\mathrm{T}$ is the temperature. Rearrangement of equation 6 and taking the logarithm of both sides of the equation, yielded equation 7

$$
\ln \left(\frac{C R}{T}\right)=\ln \left(\frac{R}{N h}\right)+\frac{\Delta S_{a d s}^{0}}{R}-\frac{\Delta H_{a d s}^{0}}{R T}
$$

The significant of equation 7 is that a plot of $\ln (\mathrm{CR} / \mathrm{T})$ versus 1/T should be linear with slope and intercept equal to $\frac{\Delta H_{a d s}^{0}}{R}$ and $\ln \left(\frac{\mathrm{R}}{\mathrm{Nh}}\right)+\frac{\Delta \mathrm{S}_{\mathrm{ads}}^{0}}{\mathrm{R}}$ respectively. Figure 4 shows the Transition state plot for the corrosion of mild steel in $1 \mathrm{M} \mathrm{H}_{2} \mathrm{SO}_{4}$ containing various concentrations of phthalic acid. Correlations obtained from the plots 
were excellent ( $\mathrm{R}^{2}$ ranged from 0.9489 to 0.9928 ). Calculated values of enthalpy and entropy changes deduced from the plots are also presented in Table 2. From the results obtained, negative values of enthalpy change suggest that the adsorption of phthalic acid onto mild steel is exothermic while positive values of entropy change indicate some degree of disorderliness. Comparing equation 4 and 6 , it is evident that the Arrhenius constant is related to change in entropy while the activation energy is related to change in enthalpy. Figure 5 shows the variation of (a) $\Delta S_{a d s}^{0}$ with $\ln (\mathrm{A})$ and (b) $\Delta H_{a d s}^{0}$ with $\mathrm{E}_{\mathrm{a}}$. The plots revealed perfect $\left(\mathrm{R}^{2}=1\right)$ and excellent $\left(\mathrm{R}^{2}=0.9836\right)$ correlations respectively, confirming that $\Delta S_{a d s}^{0}$ is related to ln (A) while $\Delta H_{a d s}^{0}$ is related to $\mathrm{E}_{\mathrm{a}}$.

The adsorption characteristics of phthalic acid for mild steel was investigated using adsorption isotherms including Langmuir, Fruendlich, Flory-Huggins, El Awardy et al., Bockris-Swinkel and Temkin isotherms. Fitness of the data obtained for the degree of surface coverage reveals that Langmuir model best described the adsorption of phthalic acid on the surface of mid steel. The Langmuir adsorption model can be expressed as follows [11],

$$
\log \left(\frac{C}{\theta}\right)=\log b_{a d s}-\log C
$$

Where $\mathrm{C}$ is the concentration of phthalic acid in the bulk electrolyte, $\theta$ is the degree of surface coverage of the inhibitor and $b_{\text {ads }}$ is the equilibrium constant of adsorption, which is related to the standard free energy of adsorption according to equation 9 [12],

$$
{ }^{*} b_{a d s}=-\frac{1}{55.5} \exp \left(\frac{\Delta G_{a d s}^{0}}{R T}\right)
$$

Figure 6 shows the Langmuir plots developed through equation 8 , while adsorption parameters (including values of, $\Delta G_{a d s}^{0}$ calculated from equation 9) deduced from the Langmuir plots are presented in Table 3. Slope values were seen to approximate unity, which suggested that there is little or no interaction between the inhibitor and the metal. Excellent correlations obtained for the different temperatures studied confirm the application of Langmuir isotherm to the adsorption of phthalic acid on mild steel. Calculated values of the free energy are within the range of values expected for the mechanism of physical adsorption hence the adsorption of phthalic acid on the surface of mild steel is consistent with the mechanism of physical adsorption [2]

\section{FTIR study}

Figure 7 shows the FTIR of the corrosion product of mild steel withdraw from solution of $\mathrm{H}_{2} \mathrm{SO}_{4}$ (in the absence of phthalic acid) after 168 hours of immersion. The absence of absorption band in the spectrum reveal that there is no adsorption. Figure 8 shows the
FTIR spectrum of phthalic acid while Figure 9 shows the FTIR of the corrosion product of mild steel withdrawn from a solution of $\mathrm{H}_{2} \mathrm{SO}_{4}$ containing phthalic acid as an inhibitor. The presence of absorption bands between 650 and $900 \mathrm{~cm}^{-1}$ in the spectrum of phthalic acid confirms that the compound is an aromatic compound. Frequencies and peaks of IR adsorption deduced from Figures 8 and 9 are presented in Table 4. The results obtained shows at a glance that the two spectrum are not similar hence are explained as follows. $\mathrm{C}-\mathrm{H}$ stretch due to aromatic ring at 722 was shifted to $726 \mathrm{~cm}^{-1}$, C-O stretch at 1166 was shifted to $1162 \mathrm{~cm}^{-1}, \mathrm{C}=\mathrm{C}$ aromatic stretch at 1458 was shifted to 1452 $\mathrm{cm}^{-1}, \mathrm{C}=\mathrm{O}$ stretch due to ketone or ester was shifted from 1746 to 1726 $\mathrm{cm}^{-1}$ and the $\mathrm{OH}$ stretch due to carboxylic acid was shifted from 2925 to $2921 \mathrm{~cm}^{-1}$. These shifts indicate that there is interaction between the mild steel and the phthalic acid [13].

On the other hands, some adsorption bands observed in the spectrum of the phthalic acid, were absent in the spectrum of the corrosion product. These included $\mathrm{CH}$ aromatic bending at $7469 \mathrm{~cm}^{-1}$ and $\mathrm{CH}$ stretch due to alkane at $2825 \mathrm{~cm}^{-1}$. On the other hand, new IR absorption bands were formed including $\mathrm{CH}$ stretch due to metal di-substituted benzene, and N-H stretch due to amide. The absence of some IR absorption bands and the formation of new one clearly reveal that the functional groups or bonds were used for the adsorption of phthalic acid on the surface of mild steel. The $\mathrm{CH}$ stretch due to metal di-substituted benzene clearly revealed that phthalic acid is adsorbed on mild steel surface.

\section{SEM study}

Figure 10 shows the scanning electron micrograph of mild steel without and with phthalic acid as a corrosion inhibitor for the metal in solution of $\mathrm{H}_{2} \mathrm{SO}_{4}$. The micrographs were taken at magnifications of $1000 \mathrm{x}, 1500 \mathrm{x}$ and $5000 \mathrm{x}$. A close examination of the micrographs obtained from the corrosion product of mild steel without the present of the inhibitor revealed that the metal was adversely affected by corrosion but the formation of protective layer is seen in the micrographs obtained from the corrosion product of mild steel (in the presence of an inhibitor). Therefore, pthalic acid prevented mild steel by forming a protective layer on its surface.

\section{Quantum chemical study}

Quantum chemical principles have been widely applied in corrosion studies. The use of frontier molecular energies to predict the electron donating ability of an inhibitor (i.e energy of the highest occupied molecular orbital, $\mathrm{E}_{\mathrm{HOMO}}$ ), the tendency to accept electron (i.e energy of the lowest unoccupied molecular orbital, $\mathrm{E}_{\text {номо }}$ ) and as a measure of the ease of reactivity (i.e energy gap), have been widely reported by many researchers [14]. Generally, the higher the value of $\mathrm{E}_{\mathrm{Hомо}}$, the greater is the tendency of an inhibitor to donate electron

\begin{tabular}{|c|c|c|c|c|c|c|c|c|c|}
\hline \multirow[b]{2}{*}{$\mathrm{C}(\mathrm{M})$} & \multicolumn{4}{|c|}{ Arrhenius parameters } & \multicolumn{5}{|c|}{ Transition state parameters } \\
\hline & slope & $\operatorname{lnb}_{\text {ads }}$ & $\begin{array}{c}E_{a} \\
(\mathrm{~J} / \mathrm{mol})\end{array}$ & $\mathbf{R}^{2}$ & slope & intercept & $\begin{array}{c}\Delta S_{\text {ads }}^{0} \\
(J / m o l)\end{array}$ & $\begin{array}{c}\Delta \boldsymbol{H}_{\text {ads }}^{0} \\
(\boldsymbol{J} / \boldsymbol{m o l})\end{array}$ & $\mathbf{R}^{2}$ \\
\hline Blank & 1.3468 & -4.1116 & 11.20 & 0.9703 & 1.0321 & -10.8640 & 982.46 & -8.58 & 0.9489 \\
\hline 0.002 & 2.1789 & -1.8224 & 18.12 & 0.9895 & 1.8642 & -8.5750 & 1001.49 & -15.50 & 0.9861 \\
\hline 0.004 & 2.1565 & -1.9523 & 17.93 & 0.9760 & 1.8418 & -8.7050 & 1000.41 & -15.31 & 0.9673 \\
\hline 0.006 & 1.7000 & -3.1424 & 14.13 & 0.9954 & 1.4852 & -9.8951 & 990.52 & -12.35 & 0.9928 \\
\hline 0.008 & 1.6591 & -3.7256 & 13.79 & 0.9898 & 1.3445 & -10.478 & 985.67 & -11.18 & 0.9844 \\
\hline 0.010 & 1.9062 & -3.0255 & 15.85 & 0.9689 & 1.5915 & -9.7782 & 991.49 & -13.23 & 0.9569 \\
\hline
\end{tabular}
[15]. On the other hand, the lower the value of $\mathrm{E}_{\mathrm{LUMO}}$, the better is

Table 2: Arrhenius and transition state adsorption parameters for the corrosion of mild steel in $0.1 \mathrm{M} \mathrm{H}_{2} \mathrm{SO}_{4}$ containing various concentrations of phthalic acid. 


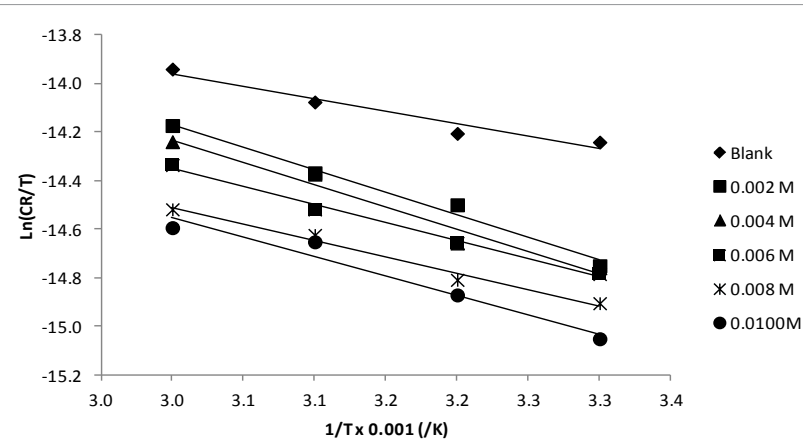

Figure 4: Transition state plot for the corrosion of mild steel in $0.1 \mathrm{M} \mathrm{H}_{2} \mathrm{SO}_{4}$ containing various concentrations of phthalic acid.

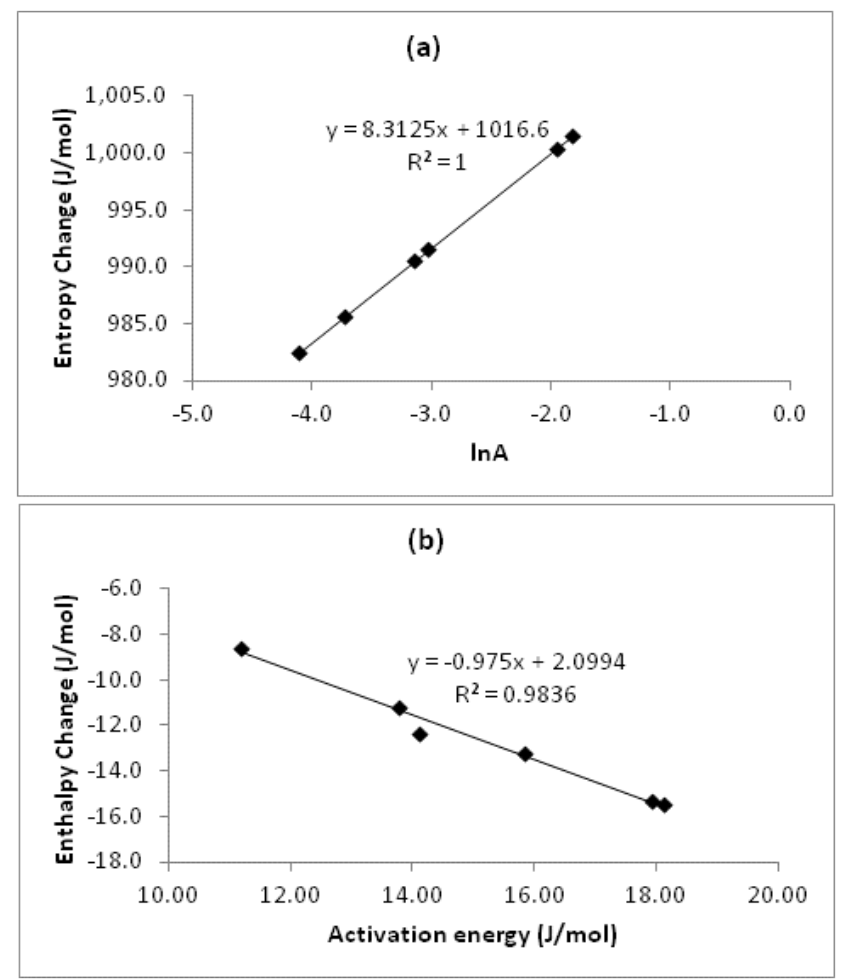

Figure 5: Variation of (a) standard entropy change with $\ln ($ Arrhenius parameter) (b) standard enthalpy change with activation energy for the adsorption of phallic acid on the surface of mild steel.

the tendency of an inhibitor to accept electron while the energy gap is an index that signify the hardness or softness of a molecule (soft molecules are more reactive than hard molecules). Other quantum chemical parameters of interest are the dipole moment, the, the total energy of the molecule $\left(\mathrm{E}_{\mathrm{T}}\right)$, the electronic energy $\left(\mathrm{E}_{\mathrm{E}}\right)$, the binding energy $\left(\mathrm{E}_{\mathrm{b}}\right)$, the heat of formation $\left(\mathrm{H}_{\mathrm{f}}\right)$, core core interaction energy $\left(\mathrm{E}_{\mathrm{CCI}}\right)$, Isolated energy $\left(\mathrm{E}_{\text {isol }}\right)$ and dipole moment $(\mu)$. Values of these parameters, calculated from various Hamiltonians are presented in Table 5. The results clearly revealed that values of $\mathrm{E}_{\text {номо }}$ were negative for all the Hamiltonians except for ZINDO 1 and TNDO 1. On the other hand, values of $\mathrm{E}_{\mathrm{LUMO}}$ were negative for PM3, AM1, RM1 and MNDO Hamiltonians while calculated values of the energy gap were all positive,. The differences in the the calculated quantum parameters for the various Hamiltonians is justified by the different assumptions that establish the respective model. Generally, the results obtained for the frontier molecular orbital energies are within the range of values reported for some good corrosion inhibitors. Similar observations were upheld for other calculated quantum chemical parameters.

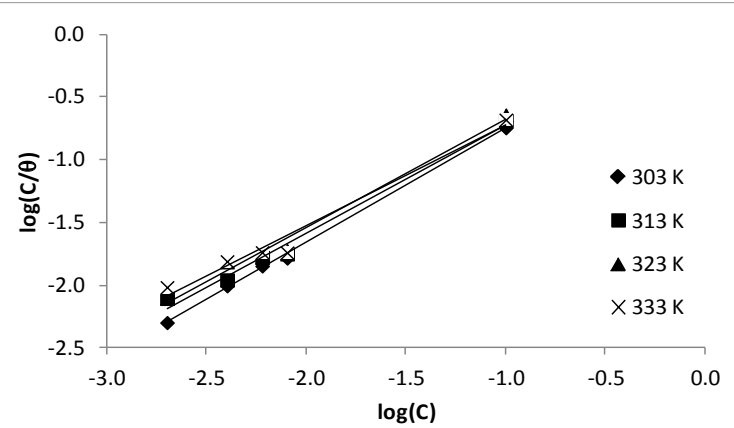

Figure 6: Langmuir isotherm for the adsorption of phthalic acid on mild steel surface.

\begin{tabular}{|c|c|c|c|c|}
\hline $\mathbf{T}(\mathbf{K})$ & slope & Logb $_{\text {ads }}$ & $\Delta \boldsymbol{G}_{\text {ads }}^{0}\left(\frac{\boldsymbol{k J}}{\boldsymbol{m o l}}\right)$ & $\mathbf{R}^{\mathbf{2}}$ \\
\hline 303 & 0.9101 & 0.1606 & -11.03 & 0.9987 \\
\hline 313 & 0.8611 & 0.1382 & -11.26 & 0.9879 \\
\hline 323 & 0.8614 & 0.1829 & -11.89 & 0.9843 \\
\hline 333 & 0.8017 & 0.0734 & -11.56 & 0.9749 \\
\hline
\end{tabular}

Table 3: Langmuir parameters for the adsorption of phthalic acid on the surface of mild steel.

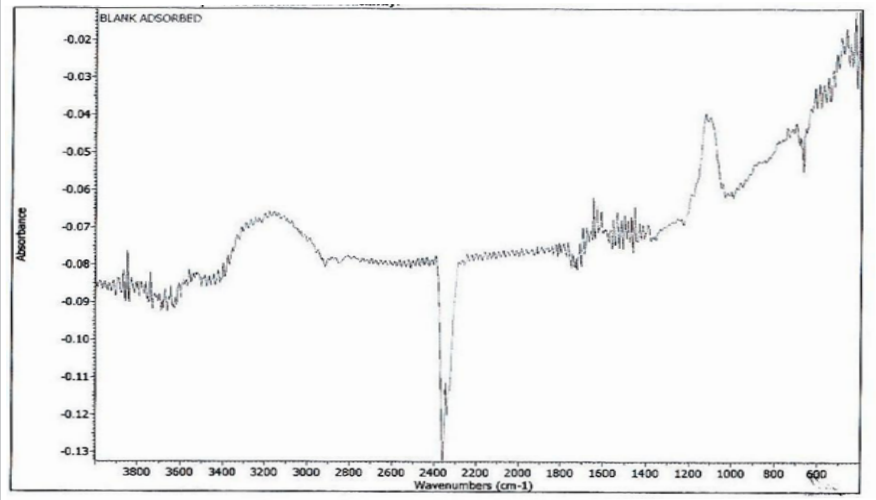

Figure 7: FTIR spectrum of the corrosion product of mild steel in the absence of inhibitor.

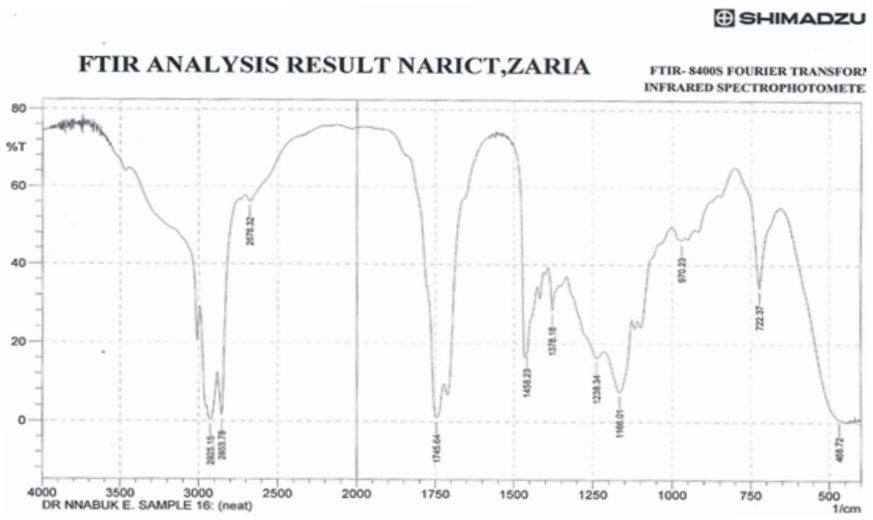

Figure 8: FTIR of phthalic acid. 


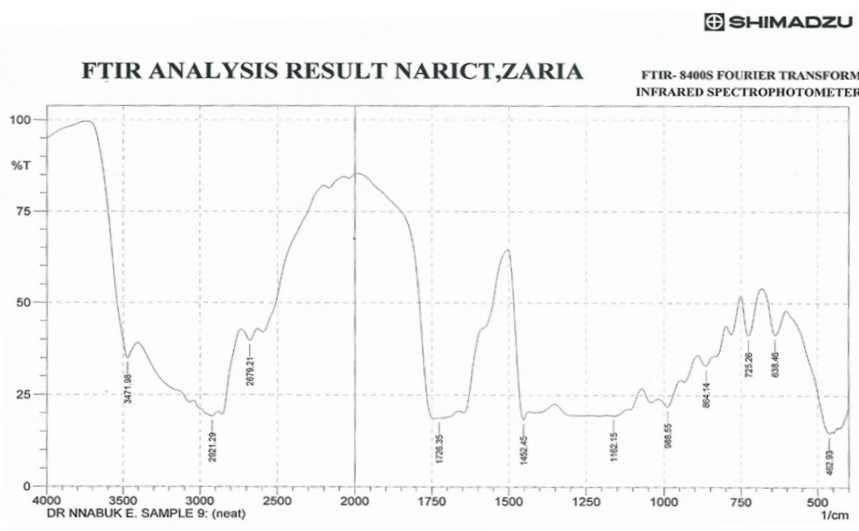

Figure 9: FTIR of corrosion product of mild steel in the presence of phthalic acid as an inhibitor.

\begin{tabular}{|c|c|c|c|c|}
\hline \multicolumn{2}{|c|}{$\begin{array}{l}\text { Phthalic acid before } \\
\text { adsorption }\end{array}$} & \multicolumn{2}{|c|}{$\begin{array}{l}\text { Phthalic acid after } \\
\text { adsorption }\end{array}$} & \multirow[b]{2}{*}{ Functional group/assignment } \\
\hline $\begin{array}{l}\text { Frequency } \\
\left(\mathrm{cm}^{-1}\right)\end{array}$ & intensity & $\begin{array}{l}\text { Frequency } \\
\left(\mathrm{cm}^{-1}\right)\end{array}$ & Intensity & \\
\hline & & 638.46 & 41.387 & $\begin{array}{l}\text { C-H stretch due to di-substituted } \\
\text { alkene }\end{array}$ \\
\hline 722.37 & 34.208 & 725.26 & 41.281 & Aromatic $\mathrm{C}-\mathrm{H}$ bending \\
\hline \multirow[t]{2}{*}{7468.72} & 0.623 & & & Aromatic $\mathrm{C}-\mathrm{H}$ bending \\
\hline & & 864.14 & 33.004 & $\begin{array}{l}\text { C-H stretch due to metal di- } \\
\text { substituted benzene }\end{array}$ \\
\hline 1166.01 & 7.591 & 1162.15 & 19.421 & $\begin{array}{l}\text { C-O stretch due to carboxylic } \\
\text { acid }\end{array}$ \\
\hline 1458.23 & 17.857 & 1452.45 & 18.390 & $\mathrm{C}=\mathrm{C}$ aromatic stretch \\
\hline 1745.64 & 0.929 & 1726.35 & 18.755 & $\begin{array}{l}\mathrm{C}=\mathrm{O} \text { stretch due to ketone or } \\
\text { ester }\end{array}$ \\
\hline 2676.32 & 56.231 & 2678.21 & 39.819 & $\mathrm{OH}$ stretch due to carboxylic acid \\
\hline 2853.78 & 1.598 & & & $\mathrm{C}-\mathrm{H}$ stretch due to alkane \\
\hline \multirow[t]{2}{*}{2925.15} & 0.266 & 2921.29 & 19.144 & $\mathrm{OH}$ stretch due to carboxylic acid \\
\hline & & 3471.98 & 34.943 & $\mathrm{NH}$ stretch \\
\hline
\end{tabular}

Table 4: Frequencies and peak of IR absorption by phthalic acid and the corrosion product of mild steel in the presence of phthalic acid.

It has been found that most corrosion inhibition involves the donation and acceptance of electron indicating that it involves nucleophilic and electrophilic reactions. Usually the inhibitor donate electron (that is it act as a nucleophile) while the metal accepting electron act as an electrophile [16]. However, it has been found that, apart from donating electron, the inhibitor can also accept electron from vacant $\mathrm{d}$ - orbital of the metal leading to the formation of a feedback bond [17]. This concept of modelling nucleophilic and electrophilic behaviour of corrosion inhibitors are packaged in the Fukui function. The Fukui function considers nucleophilic and electrophilic reactivity of an inhibitor in terms of local reactivity, that residing in a given atom or bond in the inhibitor's molecule. According to Eddy et al. [18], the Fukui function can formally be defined as

$$
f(r)=\left[\frac{\delta \mu}{\delta v(r)}\right]_{N}
$$

Where $\mathrm{v}(\mathrm{r})$ is the external potential and the functional derivatives must be taken at constant number of electrons. Assuming that the total energy $\mathrm{E}$ as a function of $\mathrm{N}$ and functional of $\mathrm{v}(\mathrm{r})$ is an exact differential, therefore, applying the Maxwell relations, equation 10 can be simplified to the following form [19],

$$
f(r)=\left(\frac{\delta \rho(r)}{\delta N}\right)_{V}
$$

It is obvious from equation 11 that due to the discontinuity of the chemical potential at integer $\mathrm{N}$, the derivative will be different if taken from the right or the left side. Therefore there are three different forms of Fukui functions, viz, $\mathrm{f}^{+}(\mathrm{r})$ (when $\mathrm{N}$ increases from $\mathrm{N}$ to $\mathrm{N}+$ $\delta), f^{-}(r)$ corresponding to a situation when $\mathrm{N}$ decreases to $\mathrm{N}-\delta$ ) and $f^{0}(r)$ the average of the two. In practice, condensed Fukui functions for electrophilic and nucleophlic attacks are defined as follows,

$$
\begin{aligned}
& f_{k}^{-}=q_{k}(N)-q_{k}(N-1) \\
& f_{k}^{+}=q_{k}(N+1)-q_{k}(N)
\end{aligned}
$$
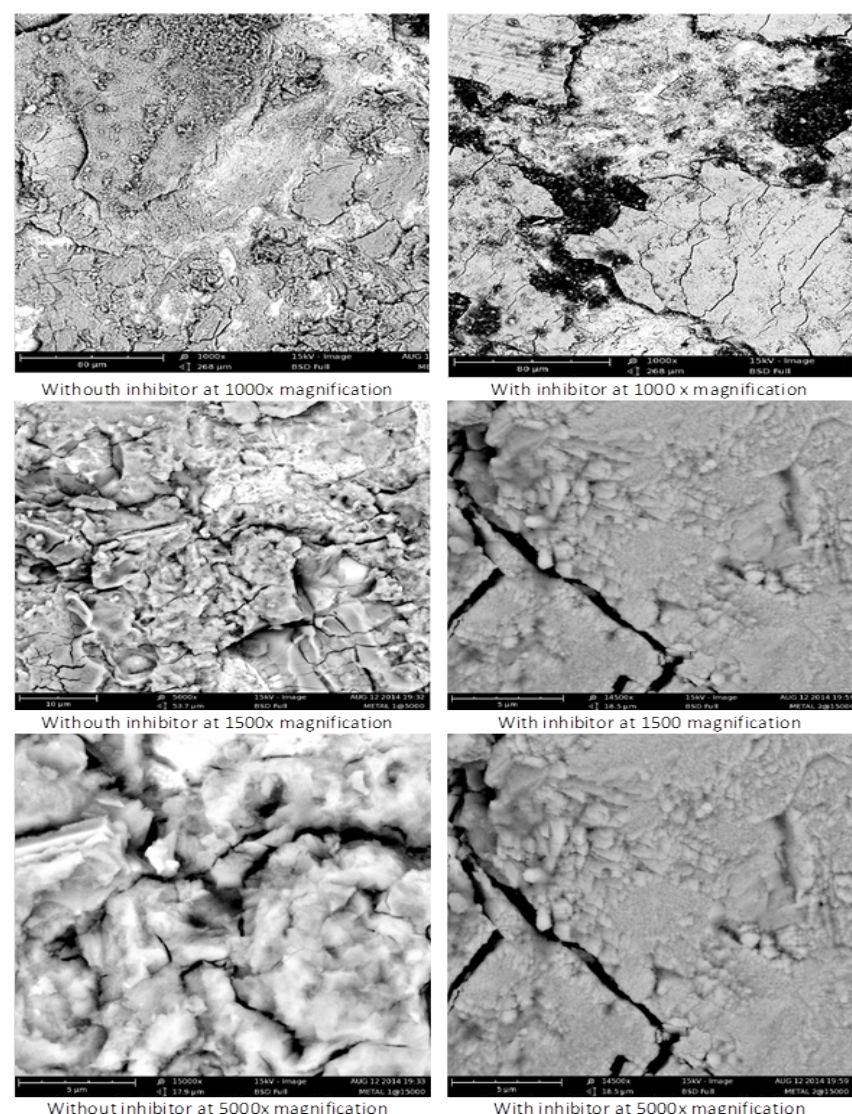

Figure 10: Scanning electron micrographs of the corrosion product of mild steel in the absence and presence of phthalic acid (as an inhibitor) at various magnifications.

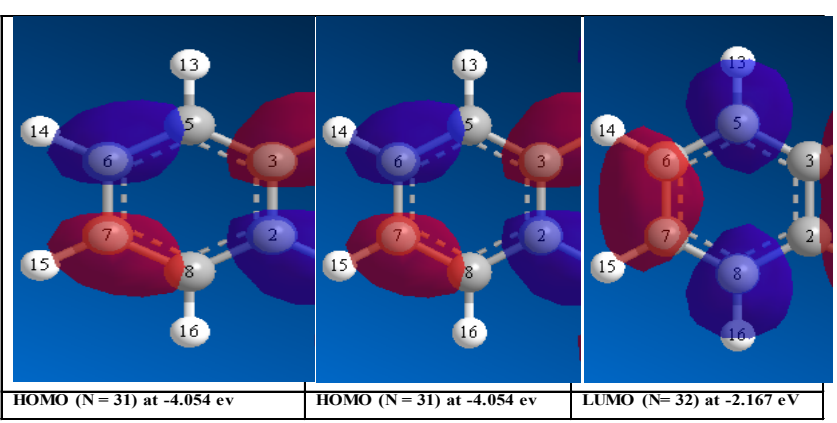

Figure 11: Homo and LUMO diagrams of phthalic acid calculated from extended Huckel theory. 


\begin{tabular}{|c|c|c|c|c|c|c|c|c|c|c|}
\hline miltonian & $\mathbf{E}_{\text {номо }}(\mathbf{e v})$ & $\mathbf{E}_{\text {LUMо }}(\mathbf{e V})$ & $\mathbf{E}_{\mathbf{L - H}}(\mathbf{e V})$ & $\mathbf{E}_{\mathbf{b}} \mathbf{( e V )}$ & $\begin{array}{c}\mathbf{E}_{\mathbf{E}} \\
\mathbf{( e V})\end{array}$ & $\mathbf{E}_{\mathbf{c C l}}(\mathbf{e V})$ & $\mathbf{E}_{\text {isol }}(\mathbf{e V})$ & $\begin{array}{c}\mu \\
\mathbf{( D e b y e )}\end{array}$ & $\mathbf{H}_{\mathbf{f}}(\mathbf{e V})$ & $\mathbf{E}_{\mathbf{T}}(\mathbf{e V})$ \\
\hline INDO & -12.603 & 2.082 & 14.685 & -243.538 & -12855.261 & 9333.264 & -3278.459 & 0.700 & -160.367 & -3521.997 \\
\hline PM3 & -1.688 & -0.213 & 1.475 & -93.414 & -11597.309 & 9266.980 & -2236.914 & 1.284 & -2.833 & -2330.329 \\
\hline AMI & -10.558 & -0.835 & 9.723 & -88.422 & -10791.293 & 839.979 & -2299.344 & 1.181 & -5.251 & -2387.765 \\
\hline RMI & -1.381 & -0.213 & 1.168 & -58.787 & -11825.354 & 9346.405 & -2420.162 & 1.648 & -31.794 & -2478.981 \\
\hline MNDO & -10.337 & -0.841 & 9.496 & -88.134 & -10811.714 & 8416.404 & -2306.960 & 1.054 & -5.180 & -2395.310 \\
\hline ZINDO 1 & 4.327 & 5.414 & 1.087 & -3273.336 & -13902.190 & 10369.924 & -3273.336 & 4.014 & -0.168 & -3532.266 \\
\hline CNDO & -13.295 & 1.614 & 14.909 & -245.889 & -3669.076 & 9333.264 & -3414.514 & 0.773 & -171.391 & -3669.076 \\
\hline TNDO 1 & 1.843 & 2.069 & 0.226 & -292.740 & -14244.937 & 10369.924 & -3582.273 & 3.352 & -202.159 & -3875.013 \\
\hline
\end{tabular}

Table 5: Calculated Semi empirical parameters of phthalic acid for various Hamiltonians.

\begin{tabular}{|c|c|c|c|c|c|c|c|}
\hline Atom & $\mathbf{q}_{\text {Huckel }}$ & $\mathbf{q}_{\mathbf{N}}$ & $\mathbf{q}_{\mathbf{N}-1}$ & $\mathbf{q}_{\mathbf{N}+1}$ & $\boldsymbol{f}_{k}^{0}$ & $\boldsymbol{f}_{k}^{-}$ & $\boldsymbol{f}_{k}^{+}$ \\
\hline $\mathrm{C}(1)$ & 0.386048 & 0.301969 & 0.274602 & 0.240256 & -0.01717 & $\mathbf{0 . 0 2 7 3 6 7}$ & -0.06171 \\
\hline $\mathrm{C}(2)$ & -0.213004 & -0.010216 & 0.030333 & -0.062311 & -0.04633 & -0.04055 & -0.0521 \\
\hline $\mathrm{C}(3)$ & -0.213004 & -0.010187 & 0.011021 & -0.011437 & -0.01123 & -0.02121 & -0.00125 \\
\hline $\mathrm{C}(4)$ & 0.386048 & 0.302136 & 0.435605 & -0.219917 & -0.32776 & -0.13347 & -0.52205 \\
\hline $\mathrm{C}(5)$ & -0.030819 & -0.043343 & -0.028628 & -0.077550 & -0.02447 & -0.01472 & -0.03421 \\
\hline $\mathrm{C}(6)$ & -0.177687 & -0.055688 & -0.039475 & -0.125296 & -0.04291 & -0.01621 & -0.06961 \\
\hline $\mathrm{C}(7)$ & -0.177688 & -0.055543 & -0.029006 & -0.122944 & -0.04697 & -0.02654 & -0.0674 \\
\hline $\mathrm{C}(8)$ & -0.030818 & 0.043938 & -0.040286 & -0.064284 & -0.01200 & $\mathbf{0 . 0 8 4 2 2 4}$ & -0.10822 \\
\hline $\mathrm{O}(9)$ & -0.855581 & -0.278084 & -0.174281 & -0.311122 & -0.06842 & -0.1038 & -0.03304 \\
\hline $\mathrm{O}(10)$ & 0.350235 & -0.365118 & -0.318693 & -0.320429 & -0.00087 & -0.04643 & $\mathbf{0 . 0 4 4 6 8 9}$ \\
\hline $\mathrm{O}(11)$ & -0.855582 & -0.278733 & 0.048488 & -0.348535 & -0.19851 & -0.32722 & -0.0698 \\
\hline $\mathrm{O}(12)$ & 0.350235 & -0.305006 & -0.179543 & -0.334895 & -0.07768 & -0.12546 & -0.02989 \\
\hline
\end{tabular}

Table 6: Huckel/Mulliken charges and condensed Fukui functions of phthalic acid, calculated from Ab initio method.

\begin{tabular}{|c|c|c|c|c|c|c|}
\hline Atom & $\mathbf{q}_{\mathbf{N}}$ & $\mathbf{q}_{\mathrm{N}-1}$ & $\mathbf{q}_{\mathrm{N}-1}$ & $\boldsymbol{f}_{k}^{0}$ & $\boldsymbol{f}_{k}^{-}$ & $\boldsymbol{f}_{k}^{+}$ \\
\hline $\mathrm{C}(1)$ & -0.091099 & 0.102721 & -0.222558 & -0.16264 & -0.19382 & -0.13146 \\
\hline $\mathrm{C}(2)$ & 0.185689 & -0.146917 & -0.090197 & 0.028358 & $\mathbf{0 . 3 3 2 6 0 6}$ & -0.27589 \\
\hline $\mathrm{C}(3)$ & 0.141555 & -0.066396 & -0.060184 & 0.003106 & 0.207951 & -0.20174 \\
\hline $\mathrm{C}(4)$ & -0.075588 & 0.030622 & 0.055125 & 0.012252 & -0.10621 & $\mathbf{0 . 1 3 0 7 1 3}$ \\
\hline $\mathrm{C}(5)$ & -0.023819 & 0.232942 & 0.040272 & -0.09633 & -0.25676 & $\mathbf{0 . 0 6 4 0 9 1}$ \\
\hline $\mathrm{C}(6)$ & 0.121354 & 0.104573 & -0.097221 & -0.1009 & 0.016781 & -0.21858 \\
\hline $\mathrm{C}(7)$ & 0.000662 & 0.176935 & -0.003792 & -0.09036 & -0.17627 & -0.00445 \\
\hline $\mathrm{C}(8)$ & 0.222024 & 0.073240 & 0.010202 & -0.03152 & 0.148784 & -0.21182 \\
\hline $\mathrm{O}(9)$ & 1.837873 & -0.445525 & -0.478030 & -0.01625 & 2.283398 & -2.3159 \\
\hline $\mathrm{O}(10)$ & 0.100796 & 0.15342 & 0.378856 & 0.11272 & -0.05262 & 0.27806 \\
\hline $\mathrm{O}(11)$ & 1.451357 & -0.063152 & -0.245270 & -0.09106 & $\mathbf{1 . 5 1 4 5 0 9}$ & -1.69663 \\
\hline $\mathrm{O}(12)$ & 0.406714 & 0.226028 & 0.394706 & $\mathbf{0 . 0 8 4 3 3 8}$ & 0.180686 & -0.01201 \\
\hline
\end{tabular}

Table 7: Mulliken charges and condensed Fukui functions of phthalic acid, calculated from DFT method.

Tables 6 and 7 present calculated values of condensed Fukui functions (calculated from Muliken charges) at Ab initio and DFT levels of theory. From the results obtained, values of condensed Fukui functions of phthalic acid are negative when it behaves as a radical, indicating unphysical results [20] Negative values were also obtained except for $\mathrm{C}(1)$ and $\mathrm{C}(8)$ in $f_{k}^{+}$and $\mathrm{O}(10)$ for $f_{k}^{-}$. Therefore, from $\mathrm{Ab}$ initio calculations, the site for nucleophilic attack will correspond to the bonds, $\mathrm{C}(1)-\mathrm{C}(10)$ since the highest value of $f_{k}^{-}$reside in that bond. On the other hand, if the inhibitor want to undergoes electrophilic attack, the preferable site will be at either $C(1)$ or $C(8)$. It is significant to note that DFT did not yield unphysical result for radical attack but identified atom $\mathrm{O}(12)$ as the preferable site and atom $\mathrm{O}(11)$ as the preferable site for nucleophlic attack while atom $\mathrm{C}(4)$ was identified as the preferable site for electrophilic attack. The differences between predictions obtained from Ab initio and DFT calculations can be attributed to the absence of electron-electron correlation factor in $\mathrm{Ab}$ ignition model. DFT is based on the assumption that the energy of molecular specie can be estimated from the energy of electron [21]. In order to further address the differences in results obtained from the two levels of approximations, Huckel charges of all the atoms in the inhibitor were calculated and the results obtained were also recorded in Table 6. Generally, model presents the atom with the highest negative charge as the one that should correspond to the preferable site for nucleophilic attack while the one with the highest positive charge as the preferable site for electrophilic attack. From the results obtained (Table 6), there is agreement between Huckel and DFT calculation (i.e $\mathrm{O}(11)$ for nucleophilic attack and $\mathrm{C}(4)$ for electrophilic attack). We also calculated the bond length between $\mathrm{C}(4)-\mathrm{O}(11)$ and 
Citation: Ameh PO, Koha PU, Eddy NO (2015) Experimental and Quantum Chemical Studies on the Corrosion Inhibition Potential of Phthalic Acid for Mild Steel in $0.1 \mathrm{M} \mathrm{H}_{2} \mathrm{SO}_{4}$. Chem Sci J 6: 100. doi:10.4172/2150-3494.1000100

between $\mathrm{C}(1)-\mathrm{O}(9)$ and the results obtained were 2.6258 and $1.280 \AA$ respectively. The larger the bond length the more loosely bound are the electrons in that bond. The present results indicate that atom $\mathrm{O}(11)$ has a better tendency to donate electron than atom $\mathrm{O}(9)$, which has a more compressed bond. It can also be seen from the HOMO and LUMO molecular orbital diagrams of phthalic acid (Figure 11) that atom $\mathrm{O}(11)$ has a better tendency to donate electron that atom $\mathrm{O}(9)$ because the HOMO diagram of $\mathrm{O}(11)$ has a negative lobe (blue represent negative) that can easily be adsorbed on the molecule, compared to that of $\mathrm{O}(9)$, which has a positive lobe (red represent positive). It should be noted that nucleophilic Fukui function corresponds to the HOMO while electrophilic Fukui function correspond to the LUMO. Therefore we upheld the results obtained from DFT calculations in this study.

\section{Conclusion}

Phthalic acid is a good instantaneous corrosion inhibitor for mild steel in acidic medium. The inhibitor possesses hetero atoms and functional groups that facilitated the ease of its adsorption on the surface of mild steel. The adsorption of the inhibitor on mild steel surface is exothermic, spontaneous and favours the mechanism of physical adsorption while its adsorption behaviour agrees with the Langmuir adsorption model. Quantum chemical calculations reveal that the prefer site for nucleophilic and electrophylic attacks are in the $\mathrm{O}(11)$ and $\mathrm{C}(4)$ atoms respectively.

\section{References}

1. Moretti G, Guidi F, Fabris F (2013) Corrosion inhibition of the mild steel in 0.5 $\mathrm{M} \mathrm{HCl}$ by 2-butyl-hexahydropyrrolo[1,2-b][1,2]oxazole. Corr Sci 76: 206-218.

2. Eddy NO (2010) Adsorption and inhibitive properties of ethanol extract of Garcinia kola and Cola nitida for the corrosion of mild steel in $\mathrm{H}_{2} \mathrm{SO}_{4}$. Pigment Resin Technol 39: 347-353.

3. Okafor PC, Osabor V, Ebenso EE (2007) Eco friendly corrosion inhibitors: Inhibitive action of ethanol extracts of Garcinia Kola for the corrosion of aluminium in acidic medium. Pigment Resin Technol 36: 299-305.

4. Solmaz R (2014) Investigation of corrosion inhibition mechanism and stability of Vitamin $\mathrm{B} 1$ on mild steel in $0.5 \mathrm{M} \mathrm{HCl}$ solution. Corr Sci 81: 75-84.

5. Dinnappa RK, Mayanna SM (1981) Benzoic acid and substituted benzoic acid as interfacial corrosion inhibitors for copper in $\mathrm{HClO}_{4}$. J Appl Electrochem 11 $111-116$

6. Mohan R, Selvaraj SK, Sakthivel A, Amalraj J, Sahayaraj W, et al. (2014) Corrosion Inhibition by - Phthalic Acid - Zn ${ }^{2+}$ System. Int J Eng Res 4: 22-27.

7. Oguzie EE, Enenebeaku CK, Akalezi CO, Okoro SC, Ayuk AA, et al. (2010) Adsorption and corrosion-inhibiting effect of Dacryodis edulis extract on lowcarbon-steel corrosion in acidic media. J Colloid Interface Sci 349: 283-292.
8. Hamdy A, Sh N, El-Gendy N (2013) Thermodynamic, adsorption and electrochemical studies for corrosion inhibition of carbon steel by henna extract in acid medium. Egyptian Journal of Petroleum 22: 17-25.

9. Eddy NO, Momoh-Yahaya H, Oguzie EE3 (2015) Theoretical and experimenta studies on the corrosion inhibition potentials of some purines for aluminum in $0.1 \mathrm{M} \mathrm{HCl}$. J Adv Res 6: 203-217.

10. Shukla SK, Ebenso EE (2011) Corrosion Inhibition, Adsorption Behavior and Thermodynamic Properties of Streptomycin on Mild Steel in Hydrochloric Acid Medium. Int J Electrochem Sci 6: 3277-3291.

11. Ameh PO, Eddy NO (2013) Commiphora pedunculatagum as a green inhibitor for the corrosion of aluminium alloy in $0.1 \mathrm{M} \mathrm{HCl}$. Res Chem Intermed 40: 2641-2649.

12. Patel NS, Hrdlicka J, Beranek P, Pribyl M, Šnita D, et al. (2014) Extract of Phyllanthusfraternus leaves as corrosion inhibitor for mild steel in $\mathrm{H} 2 \mathrm{SO} 4$ solutions. Int J Electrochem Sci 9: 2805-2815.

13. Eddy NO (2010) Fermentation product of Streptomyces griseus (albomycin) as a green inhibitor for the corrosion of zinc in $\mathrm{H}_{2} \mathrm{SO}_{4}$. Green Chem Lett Rev 3: $307-314$.

14. Rodríguez-Valdez LM, Villamisar W, Casales M, González-Rodríguez JG Martínez-Villafane A, et al. (2006) Computational simulations of the molecular structure and corrosion properties of amidoethyl, aminoethyl and hydroxyethyl imidazolines inhibitors. Corr Sci 48 : 4053-4064.

15. Eddy NO (2010) Theoretical study on some amino acids and their potential activity as corrosion inhibitors for mild steel in $\mathrm{HCl}$. Mol Simulation 36: 354-363.

16. Ghailane T, Balkhmima RA, Ghailane, R, Souizi A, Touir R, et al. (2013) Experimental and theoretical studies for mild steel corrosion inhibition in $1 \mathrm{M}$ $\mathrm{HCl}$ by two new benzothiazine derivatives. Corr Sci 78: 317-324.

17. Eddy NO, andlta $\mathrm{BI}$ (2011) Experimental and theoretical studies on the inhibition potentials of some derivatives of cyclopenta-1,3-diene. Int J Quantum Chema 111: 3456-3473.

18. Eddy NO, Udo Jl, Ameh PO, Nsor OA, Musa MS, et al. (2014) Adsorption and quantum chemical studies on the inhibition of the corrosion of aluminum in $\mathrm{HCl}$ by Gloriosa superba (GS) gum. Chem Eng Commun 201: 1360-1383.

19. Fuentealba $P$, Perez $P$, Contreras $R(2000)$ On the condensed Fukui function J ChemPhys 113: 2544-2551.

20. Eddy NO (2011) Experimental and theoretical studies on some amino acids and their potential activity as inhibitors for the corrosion of mild steel, Part 2 . J Adv Res 2: 35-47.

21. Eddy NO, Ita $\mathrm{BI}$ (2011) Theoretical and experimental studies on the inhibition potentials of aromatic oxaldehydes for the corrosion of mild steel in $0.1 \mathrm{M} \mathrm{HCl}$. J Mol Model 17: 633-647. 